\title{
Longitudinal Study of Infant Sleep Development: Early Predictors of Sleep Regulation Across the First Year
}

\author{
Jacqueline MT Henderson (D) \\ Neville M Blampied (D) \\ Karyn G France ${ }^{2}$ \\ 'School of Psychology, Speech and \\ Hearing, Te Kura Mahi ā-Hirikapo, \\ College of Science, University of \\ Canterbury, Te Whare Wānanga \\ - Waitaha, Christchurch, New Zealand; \\ ${ }^{2}$ School of Health Sciences, University of \\ Canterbury, Te Whare Wānanga \\ o Waitaha, Christchurch, New Zealand
}

Correspondence: Jacqueline MT

Henderson

School of Psychology, Speech and

Hearing, Te Kura Mahi ā-Hirikapo,

College of Science, University of

Canterbury, Te Whare Wānanga

o Waitaha, Private Bag 4800,

Christchurch, New Zealand

Tel +6433694358

Email Jacki.henderson@canterbury.ac.nz
This article was published in the following Dove Press journal: Nature and Science of Sleep

Background: An important developmental task for infants over their first few years of life is to learn to settle to sleep with a reasonably short latency, maintain sleep through the night and coordinate with family sleeping and waking schedules. A child who can reliably do this is exhibiting self-regulated sleep. Otherwise, children's sleep may have to be other (non-self) regulated to some degree and they may exhibit pediatric sleep disturbances (e.g., extended sleep latency, and/or frequent nightwaking); these are reported by $36-45 \%$ of parents of infants between ages four to 12 months.

Purpose: To answer the question: Can infant and parent factors observed at 1 month of infant age predict which infants will have regulated sleep at 6- and 12-months of age? Prediction from 1 month has not previously been investigated.

Methods: In a prospective longitudinal study, the mothers of 52 typically developing infants completed 6-day sleep diaries at 1, 3, 6, 9 and 12 months from which a composite sleep score (CSS) was derived for each child at each month. Diary reliability was assessed once (for $54 \%$ of families) using all-night videosomnography.

Results: At 6 months, CSS scores were distributed bi-modally and thus differentiated into two groups by an empirically observed CSS cutoff score, with a majority (56\%) of infants classified as self-sleep regulated (S-R) and the rest as non-self sleep-regulated (NS-R). At 12 months, $72 \%$ could similarly be classified as S-R, while $28 \%$ exhibited some continuing sleep disturbance. Discriminant function analysis investigated the predictors of S-R vs NS-R group membership at 6 and 12 months from parent and child variables recorded at 1 month. Parent presence at sleep onset and less total infant sleep time predicted group membership at 6 months with 94\% classification accuracy, and parental presence at sleep onset and frequency of infant night wakings predicted group membership at 12 months with $85 \%$ accuracy. At 1 month, parents of infants later classified as NS-R at 6 and 12 months had higher frequencies of all settling activities than parents of those later classified as S-R.

Conclusion: Variables measured at 1 month that predicted sleep status at 6 and 12 months were parental presence at sleep onset, frequency of infant night waking and total infant sleep time. The overall frequency of parent settling activities at 1 month also clearly differentiated the two sleep groups at the older ages. Parenting behaviours are modifiable factors and thus may have the potential for preventing pediatric sleep disturbances in children.

Keywords: infant, sleep regulation, predictors, parent behavior

\section{Introduction}

In the first year of life, the sleep of infants undergoes major changes. The architecture of sleep matures from relatively undifferentiated quiet and active sleep 
phases to highly structured bi-phasic Non-rapid Eyemovement (NREM) Sleep and Rapid Eye-movement (REM) Sleep. ${ }^{1}$ Sleep also becomes entrained by a diurnal circadian rhythm such that more sleep occurs at night and more waking during daylight hours. ${ }^{2}$ Further, sleep episode duration progressively increases so that sleep becomes more consolidated and less fragmented. ${ }^{3,4}$ By 6 months of age, $50 \%$ of infants have achieved selfregulated sleep, in that they have their longest consolidated sleep period of approximately 8.5 hours during the night, ${ }^{5}$ are able to settle to sleep when sleep is scheduled with only short latency and with little parental attention required, ${ }^{5}$ and are then able to resume sleep without distress or signalling to the parent when they reach the threshold of conscious awareness, which typically happens at the end of episodes of REM. ${ }^{6}$ As capacity for self-regulation increases so does the Longest Self-Regulated Sleep Period (LSRSP) - i.e. The longest period of behavioral quietude, characterised by maintaining and reinitiating sleep following an awakening or an arousal, the infant is capable of achieving. $^{5}$

Infants who do not achieve self-regulated sleep (NonSelf Sleep-Regulated, NR-S) in their first year are at risk of developing one or more forms of pediatric sleep disturbance (PSD) $)^{7-10}$ and by the end of the first year, this may manifest as a clinical concern. ${ }^{11} \mathrm{PSDs}^{7-10}$ are among the most common problems reported to pediatricians $^{12}$ by parents ${ }^{13-15}$ and include difficulty in initiating sleep (delayed sleep onset latency) when infants are first placed in the crib, and/or active resistance to attempts by parents to initiate bedtime (bed resistance). ${ }^{16}$ Once asleep, infants may wake, either frequently for relatively brief periods or for fewer longer periods, with each waking being signalled by distress and requiring caregiver assistance for sleep reinitiation. Infants may also bed-share (sometimes termed cosleeping) with their parents even where this is not desired by the family. ${ }^{16,17}$ PSD is highly prevalent, ${ }^{18}$ and within Australasia, $36-45 \%$ of parents report their infants' sleep as problematic ${ }^{19,20}$ and it may become chronic, persisting into childhood. . $^{21,22}$

PSD is distressing and stressful for the whole family and is associated with potentially serious consequences ${ }^{23}$ including increased risk of negative developmental sequelae, physical punishment, and individual and family morbidity. ${ }^{21,24-30}$ Because of these adverse effects of PSD, and because developing the capacity for sleep self-regulation in the first 12 months is protective against the development of such problems, it would be highly desirable to be able, early in infancy, to identify those variables that predict who will and will not later develop self-regulated sleep (i.e., will be classified as S-R and NS-R sleepers). ${ }^{31}$ Via further analysis of data from a larger longitudinal study investigating infant sleep maturation over the first year of life, ${ }^{2}$ the current study sought to identify parent and/or infant variables that predict the attainment of self-regulated sleep at 6 and 12 months of age, and to establish the earliest age when these can be identified. If these predictors are potentially modifiable aspects of the infant's environment, such as parenting activities, this supports giving parents/caregivers advice and guidance about how to support the optimal development of their child's sleep and thereby reduce the risk of PSD developing. Such prevention of PSD would have numerous benefits for the child, the whole family and the public health system. $^{32}$

\section{Participants and Methods \\ Participants and Study Design}

Fifty-two infants (64\% first and 25\% second born; 58\% boys) and their mothers (mean age 30.2 years) were drawn from a larger prospective longitudinal repeated-measures study ${ }^{2}$ examining sleep development over the first year of life (full study protocol is $i^{2}$ ). Participants were recruited from antenatal classes, newspaper advertisements, child health nurses, and community midwives. Inclusion criteria for the larger study were that infants were full-term, healthy at birth, and developing typically as reported by mothers and health workers. Participants were included in the current study if they returned a completed sleep diary when their infant was 1-month of age. All were born to two-parent families representative of middle socio-economic class status (SES), ${ }^{33}$ and the majority were Caucasian New Zealanders with fewer than 5\% identifying as Māori (indigenous New Zealanders). Parents were asked prospectively to record their infants' sleep for six days and nights, each month for the first 12 months. At 1-month, 89\% were exclusively breastfed. All mothers provided written informed consent and this study was conducted in accordance with the Declaration of Helsinki and was approved by the Human Ethics Committee of the University of Canterbury.

\section{Measures}

\section{Parent and Infant Sleep Measures}

The Sleep Diary ${ }^{2,34}$ was a hard-copy form ${ }^{2}$ and yielded the following measures of infant behavior: 1) frequency of 
nightwakings (>2 $\mathrm{min})$; 2) number of sleep-wake transitions over 24h; 3) LSRSP duration; and 4) total sleep time/ 24h (TST). Parent activity measures included: 1) the number of activities per night directed at settling the infant (over and above typical routine activities, including safety, e.g., checking sleeping position; care, e.g., diaper change; and being fed); 2) number of nights a parent was present at initial sleep onset; 3) number of nights the infant was placed into the crib asleep; 4) number and nature of parent interventions following a nightwaking (excluding feeding/ winding, diaper changing); and 5) number of nights of parent-infant bed sharing following a nightwaking.

The diary recorded feeding frequency and type, but the high rate of breastfeeding at 1-month precluded its use as a predictor variable.

Outcome Sleep Measure at 6 and 12 Months: The Composite Sleep Scale (CSS) ${ }^{35}$

The CSS provides a composite measure of infants' sleep. $^{35,36}$ For each six-day sleep diary six parameters were rated on a 5-point scale and summed (scored $0-4$, max score 24) including average time of sleep onset or average bedtime; total time slept at night; number of wakings per night; number of nights waking per week; time awake per waking; and average weekly hours bedsharing (co-sleeping). Higher scores indicate worse sleep.
An empirically determined cut-off score $\geq 8$ (see below) differentiated categories of good and poor sleep at age 6 months and the established clinical cut-off score of $\geq 5$ was used at 12 months. ${ }^{36,37}$ The CSS is internally consistent $(\alpha=0.77)$ and correlates well with objective sleep data. ${ }^{38,39}$

\section{Infant Sleep Group Status: Bimodal Distribution of Composite Sleep Scale Scores}

CSS scores at 1, 3, 6, 9 and 12 months were plotted (Figure 1) using the larger group of 75 participants ${ }^{2}$ since there was no significant difference in mean CSSscores between the study sample and the larger sample (the Cohen's $d$ Effect size [ES] was trivial, $d=0.12$ ). These distributions (Figure 1) demonstrated clear differentiation of the sample into two groups, classified as good and poor sleepers using a cut-off score of 8 at 6 months (as determined by the bimodal distribution), and 5 at 12 months (the published cut-off score). ${ }^{35-37,40}$

\section{Reliability Assessment}

Parents were invited to permit videosomnography $(V S M)^{41}$ in their homes via all-night infrared video recording of their infants while asleep for two consecutive nights for the purpose of checking the reliability of sleep diaries. There were no differences in average CSS scores or in socioeconomic status between those families (54\%)
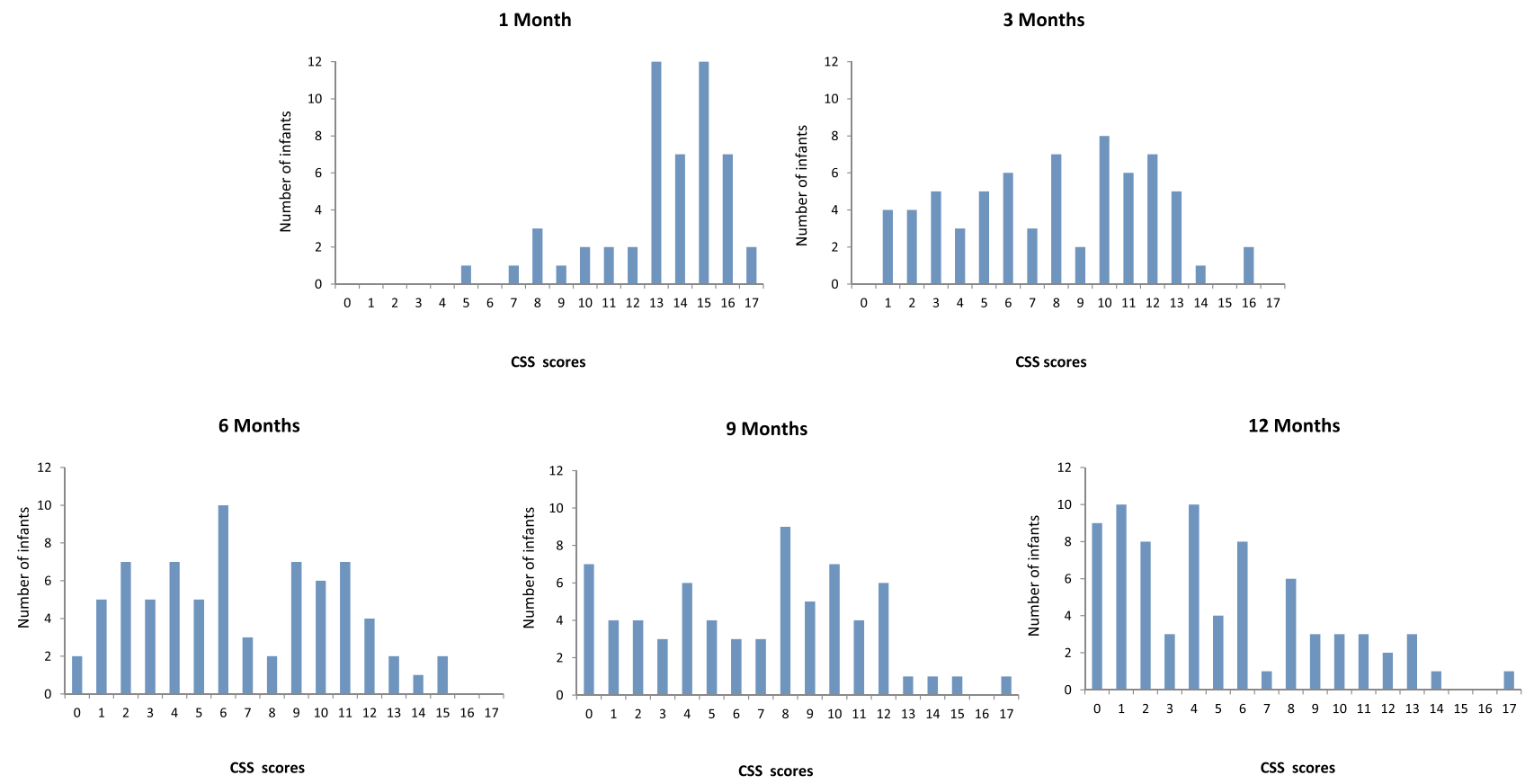

Figure I Longitudinal frequency distribution of Infant Composite Sleep Scores at I, 3, 6, 9 and I2 months of age. 
who permitted $\mathrm{VSM}^{41}$ and those that did not. There was high agreement (90-100\%) among two trained coders for the reliability check between the diaries and VSM for evening bedtime, infant state when placed into the crib, number of nightwakings, and time up in the morning.

\section{Data Analysis Steps}

The first two steps of data analysis have been described above, namely the assignment of a CSS score to each infant and their subsequent assignment to either the S-R or NS-R sleep group at 6 and 12 months using these scores. These groups were then systematically compared using one-way Analysis of Variance (ANOVA), Chi-square $\left(\chi^{2}\right)$, and the Cohen's $d$ ES, to identify the variables at 1-month that statistically and substantively significantly differentiated them. A Sidak correction was used to adjust the familywise error rate for the ANOVA tests giving a significant threshold $p<0.006$ for 9 tests. Odds ratios were calculated to examine dose-dependent frequencies of the parent variables (except bedsharing) and were coded by the proportion of nights/week on which they were recorded such that category $1=\geq 80 \%$ of nights, $2=50-79 \%$ of nights, and $3=<50 \%$ of nights. Finally, Discriminant Function Analysis ${ }^{42}$ (DFA; using SPSS 16.0) ${ }^{43}$ was used to determine which combination of these differentiating variables, measured at 1-month, best discriminated between the S-R and NS-R groups, first at 6 months and again at 12 months and, therefore, served as predictors of the development of good and poor sleep. Three variables that were univariately statistically significantly different between groups were removed from the DFA, namely nightwaking, to reduce multicollinearity with LSRSP $(r=0.7)$, and bed-sharing, measured as the count of the number of nights/week at 1-month, and placing an infant down asleep, since these were proxies for parental presence at sleep onset.

\section{Results}

The distribution of CSS-scores (Figure 1) illustrates a clear developmental trend in sleep patterns across the first year. The strong negative skew evident at 1-month was reduced by 3 months. A bimodal distribution of scores is first evident at 6 months, with a natural division at 8 , such that $56 \%$ of infants $(\mathrm{N}=29)$ could be allocated to the S-R group, with scores between $0-7 \quad(M=3.90)$, and $44 \%$ $(\mathrm{N}=23)$ to the NS-R group (scores $>8,<15 ; M=11.70)$. In support of this visual analysis, the rank order median split in CSS fell between 7-8. A relatively flat distribution at 9 months shifted to a unimodal positive skew at 12 months. Using a cut-off score of 5, $28 \%(\mathrm{~N}=15)$ of infants were classified NS-R (scored $\geq 5, M=9.5)$, and $72 \%(\mathrm{~N}=37)$ as S-R (scores $<5, M=1.96$ ) at 12 months. From ages 6 to 12 months, $21 \%$ of infants transitioned from NS-R to S-R status, whilst only 1 infant relapsed back from S-R to NS-R.

\section{One-Month Sleep Measures as Predictors of 6-Month Sleep-Group Status}

Table 1 compares variables measured at 1-month for the S-R and NS-R groups (as determined at 6 months) showing moderate to large effects on four infant and four parent variables. On average, at 1-month NS-R infants experienced a significantly shorter LSRSP (293.22 vs 353.20 mins, $d=0.65,95 \%$ CI $[0.09,1.21])$, more nightwakings (10.22 vs $6.69, d=0.95,95 \%$ CI $[-1.56,-0.40])$, less TST (801.44 vs 878.57 mins, $d=0.62,95 \%$ CI $[0.05,1.18]$ ) and more sleep-wake transitions ( 3.4 vs $2.5, d=0.61,95 \% \mathrm{CI}$ $[-1.18,-0.05])$ than the S-R infants. Parents of NS-R infants were present at sleep onset more frequently (4.86 vs 1.96 nights, $d=1.61,95 \%$ CI $[-2.21,-0.95])$ more likely to place an asleep infant into the crib (4.00 vs 1.59 nights, $d=1.32,95 \%$ CI $[-1.93,-0.72])$; bed-shared on more nights $(2.96$ vs. $0.10, \quad d=1.72, \quad 95 \% \quad$ CI $[-2.33,-1.05])$, and engaged in more activities when their child woke at night than parents of S-R infants (3.39 vs $2.55, d=0.73,95 \%$ CI $[-1.31,-0.18])$.

The differences in the rates of sleep-related behaviors between the parents of NS-R and parents of S-R sleepers are shown in Table 2. NS-R sleepers were more likely to have parents sleeping in the same bed than S-R sleepers $\left(\chi^{2}(2)\right.$ $=20.50, \mathrm{OR}_{\geq 80 \% \text { vs }<50 \%}=44.33, \mathrm{OR}_{50 \%-79 \% \text { vs }<50 \%}=4.75$, $p<0.001)$. NS-R sleepers were also more likely to be put into the crib while already asleep than S-R sleepers $\left(\chi^{2}(2)=26.36\right.$, $\left.\mathrm{OR}_{\geq 80 \% \text { vs }<50 \%}=44.00, \mathrm{OR}_{50 \%-79 \% \text { vs }<50 \%}=12.00, p<0.001\right)$. Bed-sharing was more common for the NS-R sleepers than the S-R sleepers $\left(\chi^{2}(1)=11.46, \mathrm{OR}_{\text {yes vs no }}=12.38, p<0.001\right)$.

\section{Discriminant Function Analysis: One Month Predictors of Sleep Status at 6 Months}

The five statistically significant variables in Table 1 were then entered in a DFA in order to examine their capacity to act as predictors of sleep status group membership at 6 months. A single discriminant function was significant $\chi^{2}$ $(4)=61.90, p<0.001)$ with group centroid scores of 1.43 for the S-R group and -1.80 for the NS-R group. Three significant variables loaded on the discriminant function, namely parental presence $(r=0.90)$, total sleep at 1 -month $(r=0.311)$ and nightwaking frequency $(r=0.224)$. Two 
Table I Bivariate Associations Between I-Month Infant and Parent Variable Means (SD), and Infant Sleep Status at 6 and I2 Months of Age

\begin{tabular}{|c|c|c|c|c|}
\hline I-Month Variables & $\begin{array}{l}\text { Self-Sleep Regulated Mean } \pm \\
\text { SD }\end{array}$ & $\begin{array}{l}\text { Non-Self Sleep Regulated Mean } \pm \\
\text { SD }\end{array}$ & $p$ & $\begin{array}{l}\text { Cohen's d } \\
(95 \% \mathrm{Cl})\end{array}$ \\
\hline Group Status at 6 Months & $N=29$ & $N=23$ & & \\
\hline \multicolumn{5}{|l|}{ Infant Behaviours } \\
\hline LSRSP (mins) & $353.20 \pm 94$ & $293.22 \pm 89.17$ & 0.02 & $0.65(0.09, \mid .2 I)$ \\
\hline Night waking/6 nights & $6.69 \pm 2.75$ & $10.22 \pm 4.42$ & $<0.001$ & $-0.95(-1.56,-0.40)$ \\
\hline Total Sleep Time/24h & $878.57 \pm 133.59$ & $801.44 \pm 112.59$ & 0.03 & $0.62(0.05,1.18)$ \\
\hline Sleep/Wake Transitions/24h & $5.17 \pm 1.52$ & $6.12 \pm 1.56$ & 0.03 & $-0.61(-1.18,-0.05)$ \\
\hline \multicolumn{5}{|l|}{ Parental Behaviours } \\
\hline Sleep Onset Rituals & $3.20 \pm 0.95$ & $3.34 \pm 1.09$ & 0.62 & $-0.30(-0.69,0.4 I)$ \\
\hline Night Waking Interventions & $2.55 \pm 0.95$ & $3.39 \pm 1.31$ & 0.01 & $-0.73(-1.3,-0.18)$ \\
\hline Parental Presence/6 nights & $1.96 \pm 2.06$ & $4.86 \pm 1.48$ & $<0.001$ & $-1.61(-2.21,-0.95)$ \\
\hline Placed in Crib Asleep/6 nights & $1.59 \pm 1.57$ & $4.00 \pm 2.07$ & $<0.001$ & $-1.32(-1.93,-0.72)$ \\
\hline Bed Sharing/6 nights & $0.10 \pm 0.41$ & $2.96 \pm 2.50$ & $<0.001$ & $-1.72(-2.33,-1.05)$ \\
\hline Group Status at 12 Months & $N=37$ Mean $\pm S D$ & $N=15$ Mean $\pm S D$ & & \\
\hline \multicolumn{5}{|l|}{ Infant Behaviours } \\
\hline LSRSP (mins) & $343.40 \pm 98.0$ & $285.40 \pm 79.93$ & 0.04 & $0.65(0.01,1.23)$ \\
\hline Nightwaking/6 nights & $7.22 \pm 3.35$ & $10.80 \pm 4.310$ & $<0.001$ & $-0.92(-1.61,-0.35)$ \\
\hline Total Sleep Time/24h & $854.72 \pm 123.09$ & $819.13 \pm 145.40$ & 0.37 & $0.26(-0.33,0.88)$ \\
\hline Sleep/Wake Transitions/24h & $5.40 \pm 1.56$ & $6.06 \pm 1.62$ & 0.17 & $-0.56(-1.02,-0.19)$ \\
\hline \multicolumn{5}{|l|}{ Parental Behaviours } \\
\hline Sleep Onset Rituals & $3.19 \pm 0.95$ & $3.46 \pm 1.16$ & 0.38 & $-0.25(-0.87,-0.34)$ \\
\hline Night Waking Interventions & $2.70 \pm 1.10$ & $3.47 \pm 1.25$ & 0.03 & $-0.65(-1.28,-0.06)$ \\
\hline Parental Presence/6 nights & $2.43 \pm 2.16$ & $5.26 \pm 1.2$ & $<0.001$ & $-1.34(-2.18,-0.79)$ \\
\hline Placed Crib Asleep/6 nights & $2.05 \pm 1.81$ & $4.13 \pm 2.29$ & $<0.001$ & $-0.98(-1.69,-0.42)$ \\
\hline Bed Sharing/6nights & $0.56 \pm 1.44$ & $3.33 \pm 2.53$ & $<0.001$ & $-1.41(-2.19,-0.85)$ \\
\hline
\end{tabular}

measures uniquely contributed to predicting group status and accounted for $73 \%$ of the shared variance (canonical $\left.R^{2}=0.85\right)$, namely parental presence at sleep onset $(r=0.89)$ and number of nightwakings $(r=0.30)$. Overall, the model showed strong predictive accuracy $(94.2 \%)$, correctly classifying 28/29 S-R, and 21/23 NS-R infants (Table 3A).

\section{One-Month Sleep Measures as Predictors of 12-Month Sleep Group Status}

Table 1 also compares variables measured at 1-month for the S-R and NS-R groups as determined at 12 months, showing moderate to large effects on two infant and four parent variables. On average, NS-R sleepers had shorter LSRSP durations (285.40 vs $343.40 \mathrm{~min}, d=0.65$, 95\% CI $[0.01,1.23])$, and more nightwakings (10.80 vs 7.22, $d=0.92,95 \%$ CI $[-1.61,-0.35])$ than S-R infants. Table 2 shows between-group differences in the frequency of parent activities at 1-month for the groups determined at 12 months. NS-R sleepers were more likely to have a parent present at sleep onset $\left(\chi^{2}(2)=20.50\right.$, OR $\geq 80 \%$ vs $\left.<50 \%=27.44, \mathrm{OR}_{50-79 \% \text { vs }<50 \%}=2.11, p<0.001\right)$, more likely to be put into the crib asleep $\left(\chi^{2}(2)=26.36, \mathrm{OR}_{\geq 80 \% \text { vs }<50 \%}\right.$ $\left.=28.29, \mathrm{OR}_{50 \%-79 \% \text { vs }<50 \%}=4.50, p<0.001\right)$ and bed-share following an awakening more frequently $\left(\chi^{2}(1)=9.6\right.$, $\left.\mathrm{OR}_{\text {yes vs no }}=12.38, p<0.001\right)$. In DFA, three significant predictor variables, namely parental presence $(r=0.85)$, nightwakings $(r=0.60)$, and total number of nightwaking activities $(r=0.41)$, emerged. Two measures made unique contributions in predicting group membership: parental presence at sleep onset $(r=0.75)$ and nightwakings ( $r=0.53$ ), accounting for $36 \%$ of the shared variance (canonical $\left.R^{2}=0.60\right)$. Again, the DFA showed strong predictive accuracy (84.6\%), correctly classifying $32 / 37$ of S-R and $12 / 15$ of NS-R group infants (Table $3 B$ ).

\section{Discussion}

Sleep of sufficient duration, quality, and regularity is critical to human wellbeing, health, productivity, and 
Table 2 Comparison of Parental Settling Interventions at Age I month Between Parents of Self-Sleep-Regulated and Parents of NonSelf Sleep-Regulated Sleepers at 6 and 12-Months

\begin{tabular}{|c|c|c|c|c|c|c|c|c|c|c|}
\hline \multirow{2}{*}{$\begin{array}{l}\text { I-Month Categorical } \\
\text { Variable }\end{array}$} & \multicolumn{5}{|c|}{ 6-Month Sleep Group Status } & \multicolumn{5}{|c|}{ I 2-Month Sleep Group Status } \\
\hline & $S-R(n=29)$ & $\begin{array}{l}\text { NS-R } \\
(n=23)\end{array}$ & OR & $\chi^{2}(\mathbf{d f})$ & $\boldsymbol{P}$ & $S-R(n=37)$ & $\begin{array}{l}\text { NS-R } \\
(n=15)\end{array}$ & OR & $\chi^{2}(\mathbf{d f})$ & $P$ \\
\hline \multicolumn{11}{|l|}{$\begin{array}{l}\text { \%Nights Parental } \\
\text { Presence }\end{array}$} \\
\hline$\geq 80$ & 2 & 14 & 44.33 & $20.50(2)$ & $<0.001$ & 9 & 13 & 27.44 & $23.33(2)$ & $<0.001$ \\
\hline 50-79 & 8 & 6 & 4.75 & & & 9 & I & 2.11 & & \\
\hline$<50$ & 19 & 3 & & & & 19 & I & & & \\
\hline \multicolumn{11}{|l|}{$\begin{array}{l}\text { \%Nights Placed in Crib } \\
\text { Asleep }\end{array}$} \\
\hline$\geq 80$ & 2 & 16 & 44.41 & $26.36(2)$ & $<0.001$ & 7 & 11 & 28.29 & $14.85(2)$ & $<0.001$ \\
\hline $50-79$ & 9 & 6 & 12 & & & 12 & 3 & 4.5 & & \\
\hline$<50$ & 18 & I & & & & 18 & I & & & \\
\hline \multicolumn{11}{|l|}{ Bed-sharing } \\
\hline Yes & 2 & 11 & 12.38 & $\mathrm{II} .46(\mathrm{I})$ & $<0.001$ & 5 & 9 & 9.6 & $12.4(1)$ & $<0.001$ \\
\hline No & 27 & 12 & & & & 32 & 6 & & & \\
\hline
\end{tabular}

Table 3 Classification Results for Predicted Sleep Group Status at A. Age 6 Months, and B. Age 12 Months

\begin{tabular}{|c|c|c|c|c|c|}
\hline \multirow[t]{2}{*}{$\mathbf{A}$} & & \multirow[t]{2}{*}{ 6-Month Group } & \multicolumn{2}{|l|}{ Predicted Group Status } & \multirow[t]{2}{*}{ Total } \\
\hline & & & Self-Sleep Regulated & Non-Self Sleep Regulated & \\
\hline Original & $\begin{array}{l}\text { Count } \\
\%\end{array}$ & $\begin{array}{l}\text { Sleep Regulated } \\
\text { Non-Self- Regulated } \\
\text { Sleep Regulated } \\
\text { Non-Sleep-Regulated }\end{array}$ & $\begin{array}{l}28 \\
2 \\
96.6 \\
8.7\end{array}$ & $\begin{array}{l}1 \\
21 \\
3.4 \\
91.3\end{array}$ & $\begin{array}{l}29 \\
23 \\
100.0 \\
100.0\end{array}$ \\
\hline \multirow[t]{2}{*}{ B } & & I 2-Months Group & \multicolumn{2}{|l|}{ Predicted Group Status } & \multirow[t]{2}{*}{ Total } \\
\hline & & & Self-Sleep Regulated & Non-Self Sleep Regulated & \\
\hline Original & $\begin{array}{l}\text { Count } \\
\%\end{array}$ & $\begin{array}{l}\text { Sleep Regulated } \\
\text { Non-Sleep-Regulated } \\
\text { Sleep Regulated } \\
\text { Non-Sleep-Regulated }\end{array}$ & $\begin{array}{l}32 \\
3 \\
86.5 \\
20.0\end{array}$ & $\begin{array}{l}5 \\
12 \\
13.5 \\
80.0\end{array}$ & $\begin{array}{l}37 \\
15 \\
100.0 \\
100.0\end{array}$ \\
\hline
\end{tabular}

Notes: Classification Results: $\mathbf{9 4 . 2 \%}$ of original grouped cases correctly classified. Classification Results: $84.6 \%$ of original grouped cases correctly classified.

happiness from birth to death. Foundations for this lifepromoting capacity are laid in the first years of life, when the infant's wake-sleep cycle is entrained by the circadian day-night cycle, and the infant learns to go to sleep promptly at age- and circumstance-appropriate times, sleep in synchrony with family and community requirements, and self-regulate sleep, so that sleep is resumed easily after nightwakings, without distress, disruption, or the intervention of others. Henderson et $\mathrm{al}^{5}$ described the development of infant sleep trajectories over the first year of life, focusing particularly on the development of the capacity for sleeping through the night (evidence of sleep self-regulation). The present study extends this analysis by showing, at way-points of 6 and 12 months, the clear differentiation of infants into those who can self-regulate their sleep and those who have difficulty with that, and documenting both the growth over the first year of the self-regulation capacity, such that at 12 months approximately $72 \%$ of infants were classified as S-R, the rarity of reversal from S-R to NS-R status (only one such case was observed), and yet the reality that at 12 months approximately $28 \%$ of infants were not yet self-regulated sleepers. This is consistent with other studies of sleep development in 
the first year. ${ }^{17,44}$ In the absence of comparable data on sleep trajectory development from the beginning of the second year onwards it is not possible to say with confidence what happens to this NS-R cohort, but epidemiological data show that PSD are common in early childhood, ${ }^{17,19,45}$ suggesting that failure to achieve sleep self-regulation in the first year may have enduring, adverse consequences for a substantial number of children.

This study also specifically examined factors that might predict, from age 1-month, how sleep trajectories might develop, specifically seeking to predict S-R and NS-R status at 6 and 12 months. This is the earliest age at which such a prediction has been attempted, and provides a further basis for early intervention programmes ${ }^{46}$ and preventive guidance, which might promote healthy sleep development in the first year, with enduring benefits thereafter. The DFA achieved very high predictive accuracy $(>84 \%$ at both target ages) and was consistent in identifying key predictive variables. Not surprisingly, fewer nightwakings at 1-month predicted good sleeping at 6 and 12 months. The presence of parents at initial sleep onset at 1-month predicted poor sleep at both 6 and 12 months, and at 12 months, the number of settling activities parents engaged at 1 month also predicted poorer sleep at 12 months.

These findings are consistent with models of the precipitating and maintaining factors for PSD developed by France, Henderson et al, ${ }^{16,34,40,47}$ which emphasise the importance of bed and sleep environment cues rather than parent-provided cues at sleep onset and at subsequent wakings for the development of infant sleep selfregulation. ${ }^{40,47}$ These models also emphasise the potential for parent-provided reinforcement of sleep-interfering responses emitted by the infant when initial sleep onset is delayed and when later nightwakings are signalled to contribute to PSD, consistent with the number of parent settling activities at 1-month being a predictor of NS-R status at 12 months. Further, these models, alongside transactional models of sleep development, ${ }^{48}$ propose feedback mechanisms which mutually engage and amplify parent and child behaviour in less adaptive ways. Parents who engage in more intensive responses in attempts to settle their less regulated young infants, who may be intrinsically more difficult to soothe and settle by virtue of their temperaments, ${ }^{40,49,50}$ inadvertently strengthen their child's sleep-disruptive behaviour, thereby amplifying their infant's regulation difficulties. This feedback process is predicted to result in parenting settling routines and infant sleep disturbances both becoming more frequent and intense with time, which is consistent with observations. ${ }^{16,34,40,47}$

Predicting sleep outcome at 6 months has validity both pragmatically and developmentally, since the prior five months is long enough for stability to have developed in those parent (being present at sleep-onset) and child (nightwaking) behaviours that both characterise and predict S-R and NS-R sleep status. Sleep-wake organisation changes most rapidly during this period ${ }^{5,51}$ and stability in the trajectory leading to the development of good sleep patterns is becoming well established at this age. ${ }^{4-6,52,53}$

A new finding in this study was the clear doseresponse relationship between the frequency of parental settling behaviors at 1-month and later infant sleep regulation status. Notably, every infant at 1-month of age did have a parent present when they fell asleep on more than one night of the week, so parental presence per se is not predictive of later outcomes. The critical differential (at 12 months) was that the majority (87\%) of parents of NS-R infants' were present when their infant fell asleep on 5 or $6 / 6$ nights. The odds of a NS-R infant having a parent present on $>80 \%$ of week nights compared to $<50 \%$ of nights was 27.44 higher than the odds for a S-R infant. Thus, it is the frequency and intensity of parental settling activities that have the greatest influence on their infant learning to self-soothe and thus the emergence of self-regulated sleep rather than the nature or presence of these activities, per se.

Study limitations include having only a modest sample size and one that is characterised by a relatively narrow representation of SES status and ethnicity and was drawn from only one country. Further, the data were derived from parent report, and, due to privacy concerns, not all families permitted VSM for objective recordings and reliability checks. Further systematic replications that address these limitations are clearly warranted.

\section{Conclusion}

The current study has identified the frequency of parent settling activities and of infant nightwaking at 1-month as reliable predictors of sleep regulation (i.e., of S-R and NS-R sleep status) in infants at 6 and 12 months. These novel findings help reveal important early mechanisms in the development of sleep regulation over the first year. Additionally, the study findings offer valuable information for health professionals by identifying malleable early environmental and individual risk factors for the development of 
later sleep disturbances and the associated negative developmental sequelae and family morbidity. This clarifies our understanding of infant sleep development and contributes to a growing literature aiming to prevent and thereby reduce the risks of developing chronic sleep disturbances. ${ }^{54,55}$

\section{Abbreviations}

LSRSP, longest self-regulated sleep period; PSD, pediatric sleep disturbance; CSS, Composite Sleep Scale; S-R, selfsleep-regulated; NS-R, non-self sleep-regulated; TST, total sleep time; DFA, discriminant function analysis; OR, odds ratio.

\section{Acknowledgments}

The study was supported by funding from Lotteries Health, and a University of Canterbury College of Science Post-Doctoral Fellowship (JMTH). Thank you to Dr Larry Owens for his statistical assistance and Emma Jordan for assistance with drafts of the manuscript.

\section{Author Contributions}

All authors contributed to data analysis, drafting and revising the article, gave final approval of the version to be published, and agree to be accountable for all aspects of the work.

\section{Disclosure}

The authors have no financial relationships relevant to this article or conflicts of interest to disclose.

\section{References}

1. Coons S, Guilleminault C. Development of sleep-wake patterns and non-rapid eye movement sleep stages during the first six months of life in normal infants. Pediatrics. 1982;69(6):793-798.

2. Henderson JM, France KG, Owens JL, Blampied NM. Sleeping through the night: the consolidation of self-regulated sleep across the first year of life. Pediatrics. 2010;126(5):e1081-e1087. doi:10.1542/ peds.2010-0976

3. Anders TF, Halpern LF, Hua J. Sleeping through the night: a developmental perspective. Pediatrics. 1992;90(4):554-560.

4. St James-Roberts I, Roberts M, Hovish K, Owen C. Video evidence that London infants can resettle themselves back to sleep after waking in the night, as well as sleep for long periods, by 3 months of age. J Dev Behav Pediatr. 2015;36(5):324-329.

5. Henderson JM, France KG, Blampied NM. The consolidation of infants' nocturnal sleep across the first year of life. Sleep Med Rev. 2011;15(4):211-220.

6. Anders TF, Keener M, Bowe TR, Shoaff BA. A longitudinal study of nighttime sleep-wake patterns in infants from birth to one year. Front Infant Psychiatry. 1983;1:150-170.

7. Bruni O, Ottaviano S, Guidetti V, et al. The Sleep Disturbance Scale for Children (SDSC) construction and validation of an instrument to evaluate sleep disturbances in childhood and adolescence. $J$ Sleep Res. 1996;5(4):251-261. doi:10.1111/j.1365-2869.1996.00251.x
8. Byars KC, Yeomans-Maldonado G, Noll JG. Parental functioning and pediatric sleep disturbance: an examination of factors associated with parenting stress in children clinically referred for evaluation of insomnia. Sleep Med. 2011;12(9):898-905. doi:10.1016/j.sleep.2011. 05.002

9. Esposito S, Laino D, D’Alonzo R, et al. Pediatric sleep disturbances and treatment with melatonin. $J$ Transl Med. 2019;17(1):77. doi:10. 1186/s12967-019-1835-1

10. Kuhn BR, Elliott AJ. Treatment efficacy in behavioral pediatric sleep medicine. J Psychosom Res. 2003;54(6):587-597. doi:10.1016/S00 22-3999(03)00061-8

11. Morrell JM. The infant sleep questionnaire: a new tool to assess infant sleep problems for clinical and research purposes. Child Psychol Psychiatry Rev. 1999;4(1):20-26. doi:10.1017/S136064179 8001816

12. Cook F, Conway L, Gartland D, Giallo R, Keys E, Brown S. Profiles and predictors of infant sleep problems across the first year. $J$ Dev Behav Pediatr. 2020;41(2):104-116. doi:10.1097/DBP.0000000000000733

13. Forsyth BW, Leventhal JM, McCarthy PL. Mothers' perceptions of problems of feeding and crying behaviors: a prospective study. $\mathrm{Am}$ $J$ Dis Child. 1985;139(3):269-272. doi:10.1001/archpedi.1985.021 40050063023

14. Smart J, Hiscock H. Early infant crying and sleeping problems: a pilot study of impact on parental well-being and parent-endorsed strategies for management. J Paediatr Child Health. 2007;43 (4):284-290. doi:10.1111/j.1440-1754.2007.01060.x

15. St James-Roberts I, Halil T. Infant crying patterns in the first year: normal community and clinical findings. J Child Psychol Psychiatry. 1991;32(6):951-968. doi:10.1111/j.1469-7610.1991.tb01922.x

16. France KG, Henderson JM, Hudson SM. Fact, act, and tact: a three-stage approach to treating the sleep problems of infants and young children. Child Adolesc Psychiatr Clin. 1996;5(3):581-600.

17. Hiscock H, Davey MJ. Sleep disorders in infants and children. J Paediatr Child Health. 2018;54(9):941-944. doi:10.1111/jpc.12033

18. Sadeh A, Mindell JA, Luedtke K, Wiegand B. Sleep and sleep ecology in the first 3 years: a web-based study. J Sleep Res. 2009;18(1):60-73. doi:10.1111/j.1365-2869.2008.00699.x

19. Armstrong KL, Quinn RA, Dadds MR. The sleep patterns of normal children. Med J Aust. 1994;161(3):202-205. doi:10.5694/j.13265377.1994.tb127383.x

20. Hiscock H, Wake M. Infant sleep problems and postnatal depression: a community-based study. Pediatrics. 2001;107(6):1317-1322. doi:10.1542/peds.107.6.1317

21. Magee CA, Gordon R, Caputi P. Distinct developmental trends in sleep duration during early childhood. Pediatrics. 2014;133(6): e1561-e1567. doi:10.1542/peds.2013-3806

22. Sheridan A, Murray L, Cooper PJ, Evangeli M, Byram V, Halligan SL. A longitudinal study of child sleep in high and low risk families: relationship to early maternal settling strategies and child psychological functioning. Sleep Med. 2013;14(3):266-273. doi:10.1016/j.sleep.2012.11.006

23. Gradisar M, Jackson K, Spurrier NJ, et al. Behavioral interventions for infant sleep problems: a randomized controlled trial. Pediatrics. 2016;137(6):e20151486.

24. Bayer JK, Hiscock H, Hampton A, Wake M. Sleep problems in young infants and maternal mental and physical health. J Paediatr Child Health. 2007;43(1-2):66-73. doi:10.1111/j.1440-1754.2007.01005.x

25. Byars KC, Yolton K, Rausch J, Lanphear B, Beebe DW. Prevalence, patterns, and persistence of sleep problems in the first 3 years of life. Pediatrics. 2012;129(2):e276-e284. doi:10.1542/peds.2011-0372

26. Hiscock H. Rock-a-bye baby? Parenting and infant sleep. Sleep Med Rev. 2010;14(2):85-87. doi:10.1016/j.smrv.2009.10.005

27. Hysing M, Sivertsen B, Garthus-Niegel S, Eberhard-Gran M. Pediatric sleep problems and social-emotional problems. A population-based study. Infant Behav Dev. 2016;42:111-118. doi:10. 1016/j.infbeh.2015.12.005 
28. Johnson CM. Infant and toddler sleep: a telephone survey of parents in one community. J Dev Behav Pediatr. 1991;12(2):108-114. doi:10.1097/00004703-199104000-00007

29. Mindell JA, Leichman ES, DuMond C, Sadeh A. Sleep and social-emotional development in infants and toddlers. J Clin Child Adolesc Psychol. 2017;46(2):236-246. doi:10.1080/15374416.2016. 1188701

30. Mindell JA, Owens J, Alves R, et al. Give children and adolescents the gift of a good night's sleep: a call to action. Sleep Med. 2011;12 (3):203-204. doi:10.1016/j.sleep.2011.01.003

31. Lam P, Hiscock H, Wake M. Outcomes of infant sleep problems: a longitudinal study of sleep, behavior, and maternal well-being. Pediatrics. 2003;111(3):e203-e207. doi:10.1542/peds.111.3.e203

32. El-Sheikh M, Buckhalt JA II. Moving sleep and child development research forward: priorities and recommendations from the SRCDsponsored forum on sleep and child development. Monogr Soc Res Child Dev. 2015;80(1):15-32. doi:10.1111/mono.12142

33. Elley WB, Irving JC. The Elley-Irving socio-economic index: 2001 census revision. $N$ Z J Educ Stud. 2003.

34. Healey D, France KG, Blampied NM. Treating sleep disturbance in infants: what generalizes? Behav Interventions. 2009;24(1):23-41. doi:10.1002/bin. 274

35. Richman N. A double-blind drug trial of treatment in young children with waking problems. $J$ Child Psychol Psychiatry. 1985;26 (4):591-598. doi:10.1111/j.1469-7610.1985.tb01643.x

36. Priddis LE. Tuned in parenting and infant sleep patterns. Early Child Dev Care. 2009;179(3):259-269. doi:10.1080/03004430600912132

37. France KG. Understanding and Managing Infant Sleep Disturbance. Christchurch: University of Canterbury; 1989.

38. Benoit D, Zeanah CH, Boucher C, Minde KK. Sleep disorders in early childhood: association with insecure maternal attachment. $J \mathrm{Am}$ Acad Child Adolesc Psychiatry. 1992;31(1):86-93. doi:10.1097/ 00004583-199201000-00013

39. Minde K, Popiel K, Leos N, Falkner S, Parker K, Handley-Derry M. The evaluation and treatment of sleep disturbances in young children. J Child Psychol Psychiatry. 1993;34(4):521-533. doi:10.1111/j.14697610.1993.tb01033.x

40. France KG, Blampied NM. Infant sleep disturbance: description of a problem behaviour process. Sleep Med Rev. 1999;3(4):265-280. doi:10.1053/smrv.1999.0071

41. Anders TF, Sostek AM. The use of time lapse video recording of sleep-wake behavior in human infants. Psychophysiology. 1976;13 (2):155-158. doi:10.1111/j.1469-8986.1976.tb00092.x
42. Tabachnick B, Fidell L. Using Multivariate Analysis. California State University. Northridge. New York, NY: Harper Collins College Publishers. Pub.; 2001.

43. IBM. SPSS Statistics for Windows, Version 25.0. Armonk, NY: IBM Corp.

44. Gibson R, Gander P, Elder D. Factors differentiating infants identified by parents as problem sleepers, and those that are not. Sleep Biol Rhythms. 2012;10(1):46-52. doi:10.1111/j.1479-8425.2011.00517.x

45. Zuckerman B, Stevenson J, Bailey V. Sleep problems in early childhood: continuities, predictive factors, and behavioral correlates. Pediatrics. 1987;80(5):664-671.

46. Sette S, Baumgartner E, Ferri R, Bruni O. Predictors of sleep disturbances in the first year of life: a longitudinal study. Sleep Med. 2017;36:78-85. doi:10.1016/j.sleep.2017.04.015

47. Blampied NM, France KG. A behavioral model of infant sleep disturbance. J Appl Behav Anal. 1993;26(4):477-492. doi:10.1901/ jaba.1993.26-477

48. Sadeh A, Tikotzky L, Scher A. Parenting and infant sleep. Sleep Med Rev. 2010;14(2):89-96. doi:10.1016/j.smrv.2009.05.003

49. Burnham MM, Goodlin-Jones BL, Gaylor EE, Anders TF. Nighttime sleep-wake patterns and self-soothing from birth to one year of age: a longitudinal intervention study. $J$ Child Psychol Psychiatry. 2002;43(6):713-725. doi:10.1111/1469-7610.00076

50. Sadeh A, Anders TF. Infant sleep problems: origins, assessment, interventions. Infant Ment Health J. 1993;14(1):17-34. doi:10.1002/ 1097-0355(199321)14:1<17::AID-IMHJ2280140103>3.0.CO;2-Q

51. Anders TF. Infant sleep, nighttime relationships, and attachment. Psychiatry. 1994;57(1):11-21.

52. Bruni O, Baumgartner E, Sette S, et al. Longitudinal study of sleep behavior in normal infants during the first year of life. J Clin Sleep Med. 2014;10(10):1119-1127. doi:10.5664/jcsm.4114

53. Sadeh A, Acebo C, Seifer R, Aytur S, Carskadon MA. Activity-based assessment of sleep-wake patterns during the 1st year of life. Infant Behav Dev. 1995;18(3):329-337. doi:10.1016/0163-6383(95)90021-7

54. Hiscock H, Cook F, Bayer J, et al. Preventing early infant sleep and crying problems and postnatal depression: a randomized trial. Pediatrics. 2014;133(2):e346-e354. doi:10.1542/peds.2013-1886

55. Wolfson A, Lacks P, Futterman A. Effects of parent training on infant sleeping patterns, parents' stress, and perceived parental competence. J Consult Clin Psychol. 1992;60(1):41-48. doi:10.1037/0022-006X. 60.1 .41

\section{Publish your work in this journal}

Nature and Science of Sleep is an international, peer-reviewed, open access journal covering all aspects of sleep science and sleep medicine, including the neurophysiology and functions of sleep, the genetics of sleep, sleep and society, biological rhythms, dreaming, sleep disorders and therapy, and strategies to optimize healthy sleep.
The manuscript management system is completely online and includes a very quick and fair peer-review system, which is all easy to use. Visit http://www.dovepress.com/testimonials.php to read real quotes from published authors. 